\title{
Autosomal dominant spastic paraplegia type 10
}

INSERM

\section{Source}

INSERM. (1999). Orphanet: an online rare disease and orphan drug data base. Autosomal dominant spastic paraplegia type 10. ORPHA:100991

Autosomal dominant spastic paraplegia type 10 (SPG10) is a rare type of hereditary spastic paraplegia that can present as either a pure form of spastic paraplegia with lower limb spasticity, hyperreflexia and extensor plantar responses, presenting in childhood or adolescence, or as a complex phenotype associated with additional manifestations including peripheral neuropathy with upper limb amyotrophy, moderate intellectual disability and parkinsonism. Deafness and retinitis pigmentosa were reported in one case. 